\title{
A technique to facilitate laryngeal passage during flexible bronchoscopic intubation
}

\author{
Qiusheng Ren, MD • Wanjun Yu, MD • \\ Minmin Cai, MD
}

Received: 12 February 2015/Accepted: 19 March 2015/Published online: 25 March 2015

(c) Canadian Anesthesiologists' Society 2015

\section{To the Editor,}

Flexible bronchoscope (FOB)-assisted endotracheal intubation has a well-established role in airway management. Intubation with a FOB involves two steps: first inserting the bronchoscope into the trachea and then advancing an endotracheal tube (ETT) over the FOB. Nevertheless, when advancing the ETT over the FOB, the bevelled tip of the ETT can impinge on the vocal cords, arytenoids, or other hypopharyngeal structures and impede advancement through the laryngeal inlet. ${ }^{1,2}$

To overcome this hindrance, a common maneuver involves withdrawing, rotating (anticlockwise), and repeatedly advancing the ETT, as well as altering the patient's head or neck position, external laryngeal manipulation, jaw-thrust maneuvers, and lingual traction. ${ }^{3}$ All of these measures may provide better alignment of the ETT and FOB with the laryngeal opening. Moreover, some specialized products (e.g., Aintree intubation catheter, tapered ETTs, Parker Flex-Tip ${ }^{\circledR}$ ETT) have also been used to minimize the gap between the FOB and the leading

Electronic supplementary material The online version of this article (doi:10.1007/s12630-015-0370-7) contains supplementary material, which is available to authorized users.

Q. Ren, MD ( $\square) \cdot$ M. Cai, MD

Department of Anesthesia, Yinzhou People's Hospital, Ningbo

University Medical College, Ningbo, Zhejiang, China

e-mail: renqiusheng1971@yahoo.com

W. Yu, MD

Department of Respiratory, Yinzhou People's Hospital, Ningbo University Medical College, Ningbo, Zhejiang, China edge of the ETT, thus facilitating railroading of the ETT over the FOB. A limitation of the above devices is the necessity for them to be in place prior to the start of the intubation sequence. Furthermore, the efficacy of these various products has been debated, ${ }^{4}$ and their availability is somewhat variable.

We have used an alternate technique in two cases to facilitate passage of a 7.0-mm ETT over a 3-mm FOB using a $19 \mathrm{G}$ epidural catheter. After the conventional techniques had failed and while keeping the bronchoscope in place, the ETT was withdrawn until its tip was visible. One end of an epidural catheter was then used to encircle the FOB; next, the two ends were passed through the Murphy eye of the ETT from the inside out (Figure A) and then through the lumen of the ETT (Figure B). With the catheter kept taut, the ETT (which was then tightly opposed to the FOB; see video) was then easily passed over the FOB through the laryngeal inlet. The bronchoscope was then withdrawn followed by removal of the catheter.

The epidural catheter offers advantages as it is soft and smooth and thus minimizes the chances that it might damage tissues. The rigidity of the catheter also enables it to pass easily through the ETT lumen. If the catheter breaks, it can easily be removed as both ends are visible at the ETT connector.

Although the feasibility of this technique in all patients is unclear, it may offer an advantage as it can be accomplished without the need to remove the FOB. This will save time and limit the repeated attempts at passing the FOB. For those considering this approach in their airway armamentarium, practicing the technique beforehand in a simulator may offer an advantage. Further investigation will be required to confirm the broader safety and applicability of this technique. 
Figure schematic of the technique. A) The ends of a catheter passing through the Murphy eye; B) The ends of a catheter passing through the lumen of the endotracheal tube
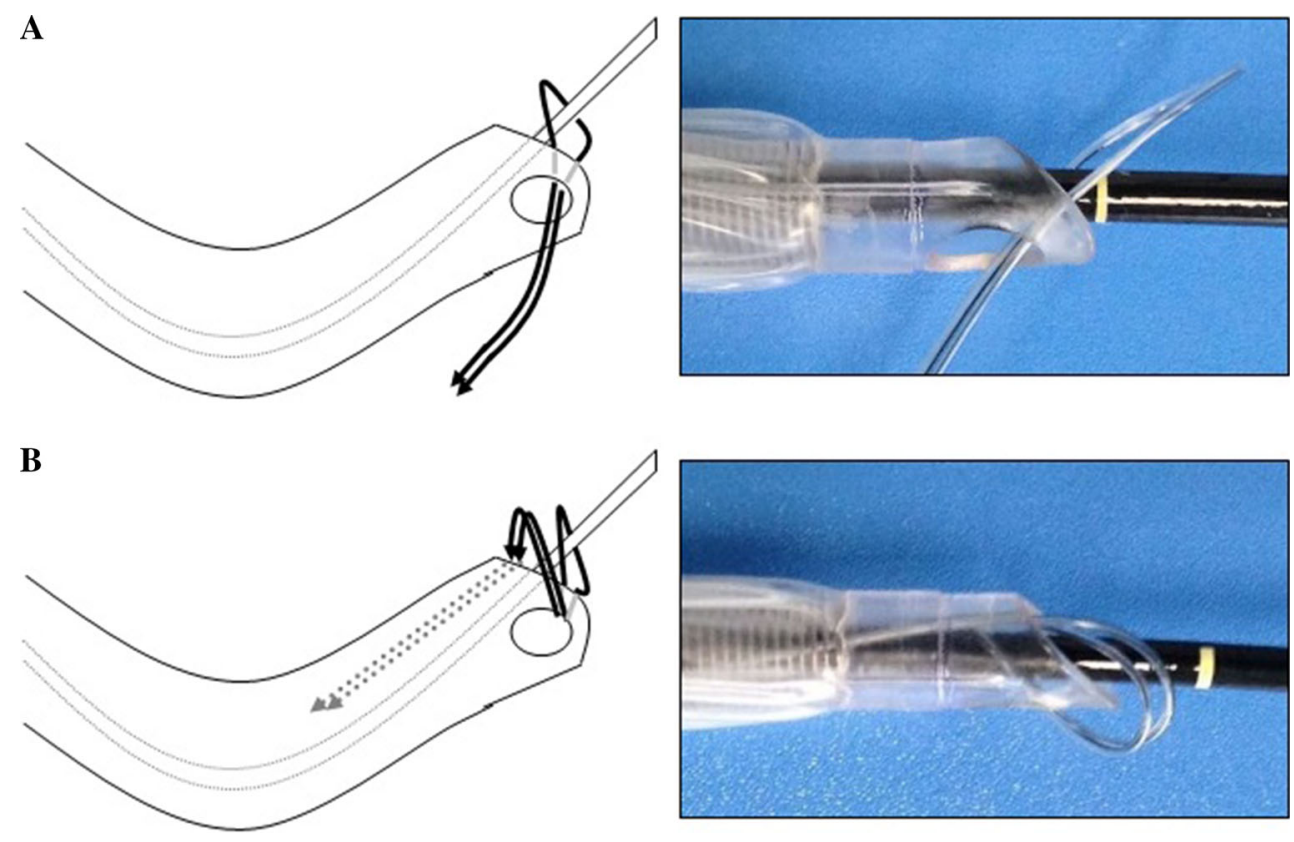

Funding This work did not require funding.

Conflicts of interest None declared.

Associations None.

\section{References}

1. Asai $T$, Shingu $K$. Difficulty in advancing a tracheal tube over a fibreoptic bronchoscope: incidence, causes and solutions. $\mathrm{Br} \mathrm{J}$ Anaesth 2004; 92: 870-81.
2. Johnson DM, From AM, Smith RB, From RP, Maktabi MA. Endoscopic study of mechanisms of failure of endotracheal tube advancement into the trachea during awake fiberoptic orotracheal intubation. Anesthesiology 2005; 102: 910-4.

3. Mangar D, Ching YH, Shah VV, Camporesi EM. Lingual traction to facilitate fibreoptic intubation in patients with difficult airways under general anesthesia. Can J Anesth 2014; 61: 889-90.

4. Ho AM, Chunq DC, Karmakar MK. Is the Parker Flex-Tip tube really superior to the standard tube for fibreoptic orotracheal intubation? Anesthesiology 2003; 99: 1237. 